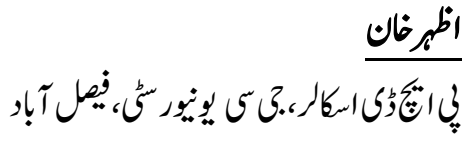

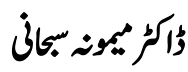

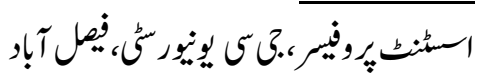

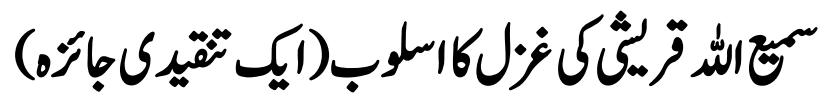

\section{Azhar Khan}

PhD Scholar, Department of Urdu, Government College University Faisalabad.

\section{Dr. Mamuna Subhani}

Assistant Professor, Department of Urdu, Government College University Faisalabad.

\section{Style of Samiullah Qureshi's Ghazal (A Critical Review)}

Prof. Samiullah Qureshi is recognized as a renowned and celebrated poet, critic and biographer. This article presents critical evaluation of the stylistic aspects of his verse (Ghazal). His poetry is embellished with the use of multiple figures of speech and poetic characteristics. Apart from the conventional fashion, he has also made use of modern poetic style. This article elaborates and illustrates the technical merits of his ghazal.

Keywords: Ghazal, Poetry, Style, Simile, Rhythm, Samiullah.

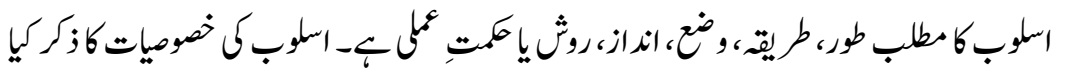

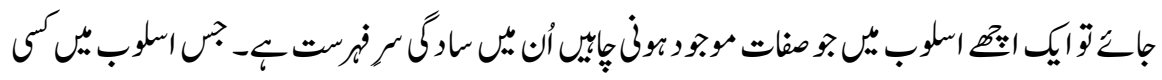

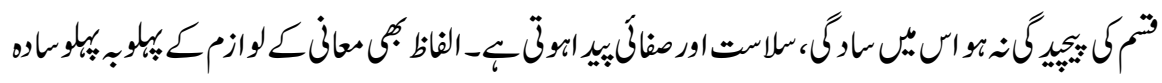

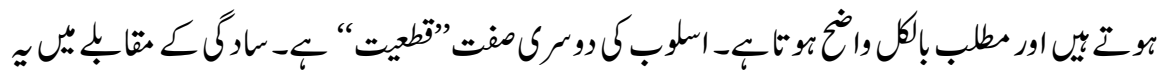

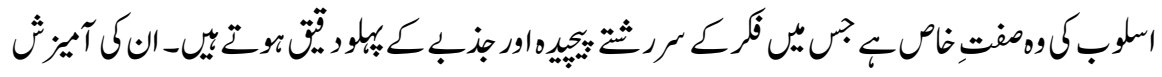

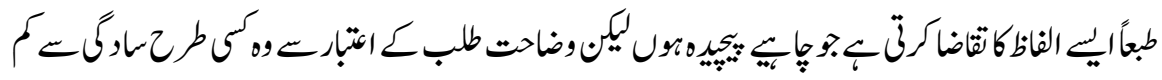

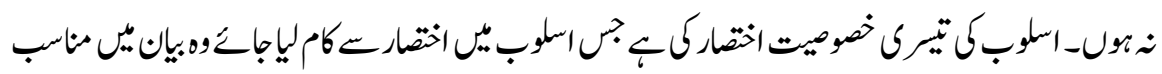




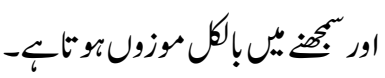

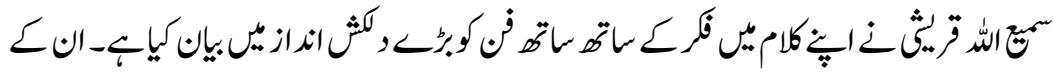

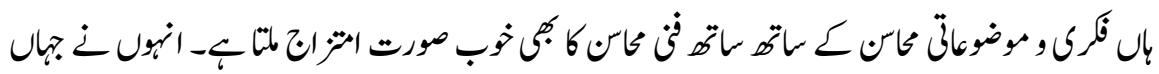

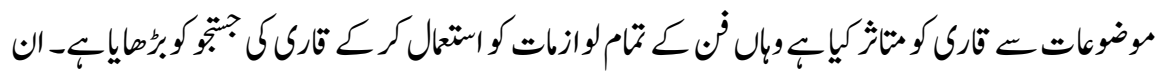

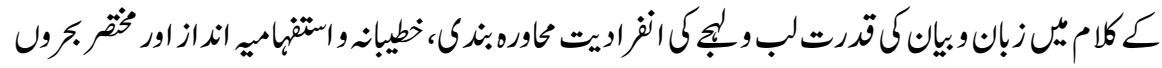

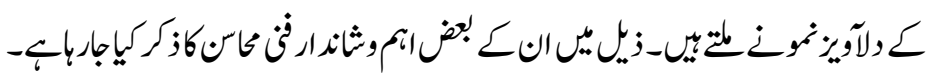

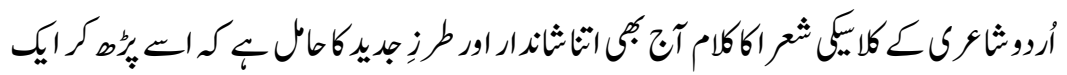

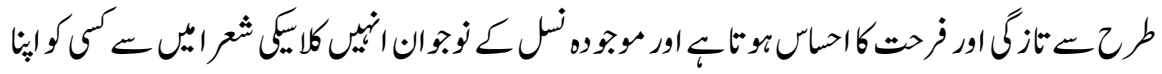

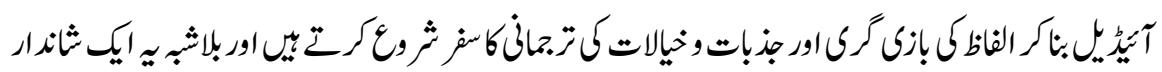

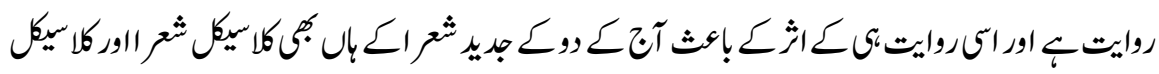

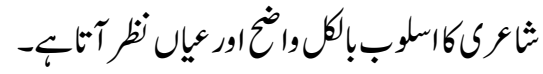

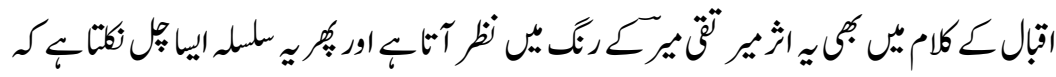

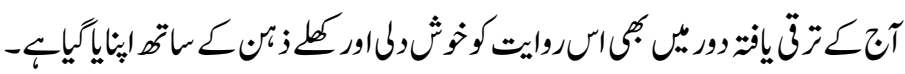

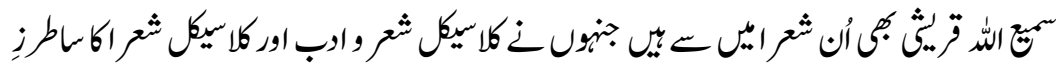

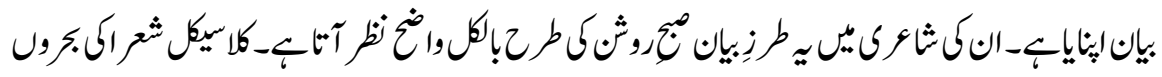

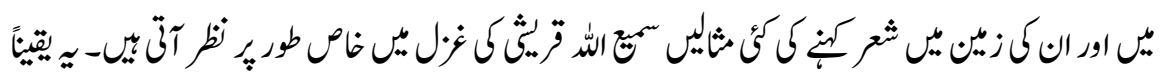

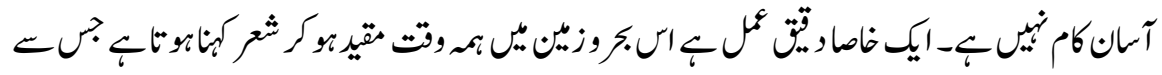

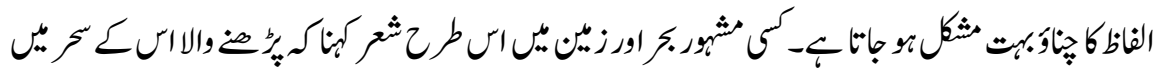

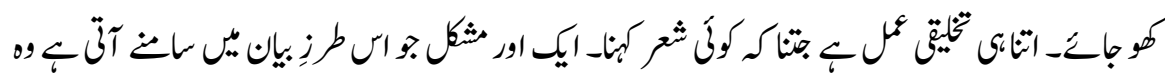

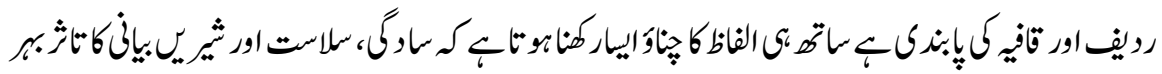

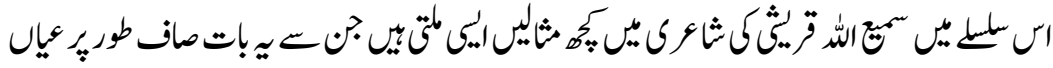

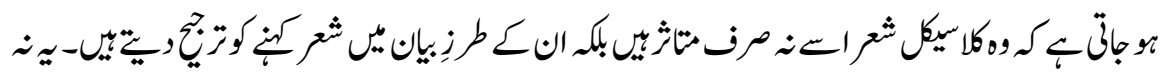




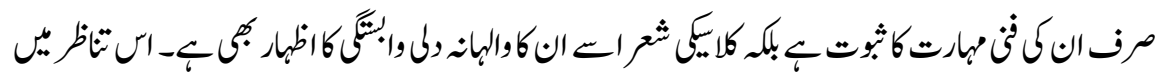

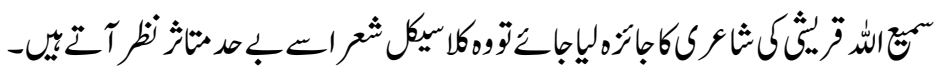

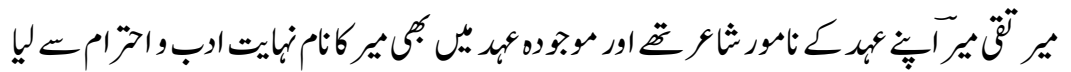

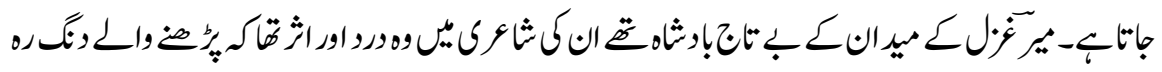

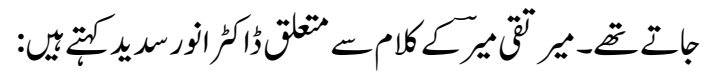

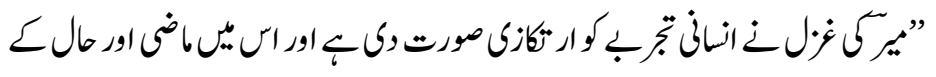

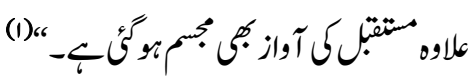

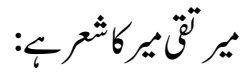

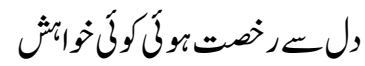

$$
\begin{aligned}
& \text { (r) }
\end{aligned}
$$

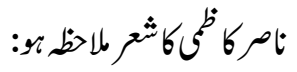

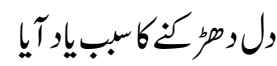

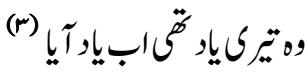

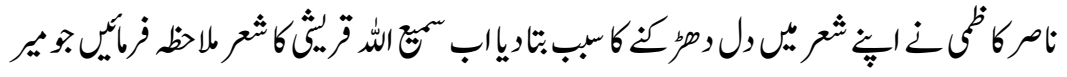

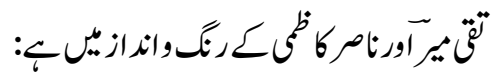

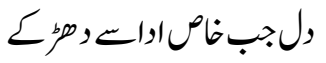

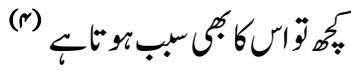

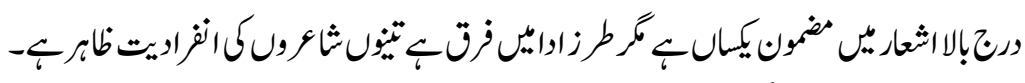

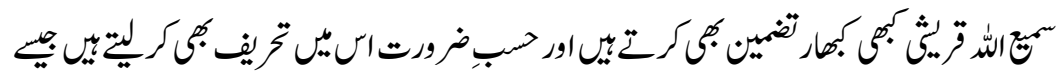

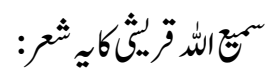

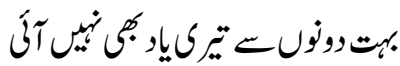

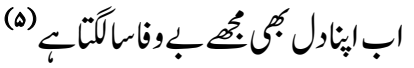

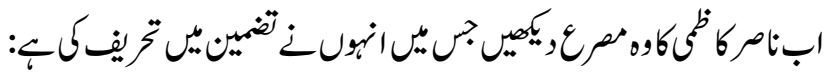




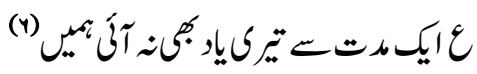

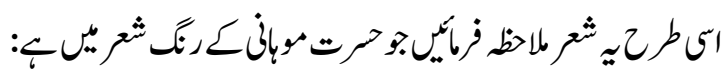

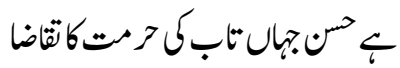

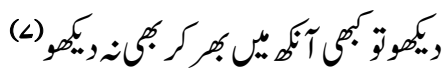

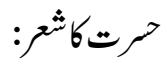

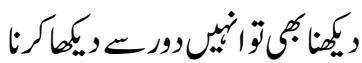

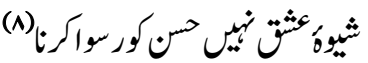

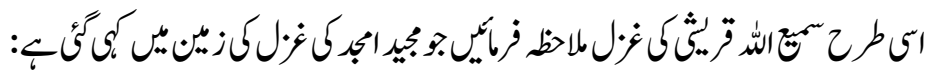

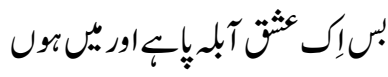

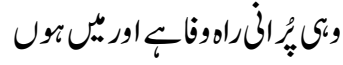

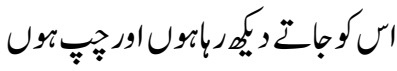

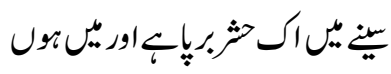

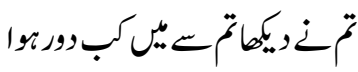

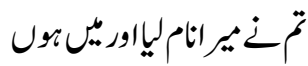

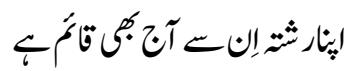

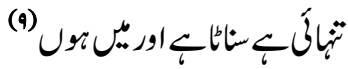

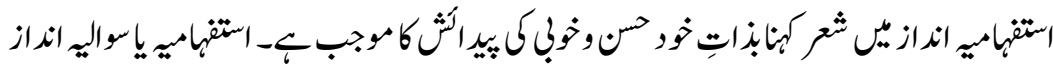

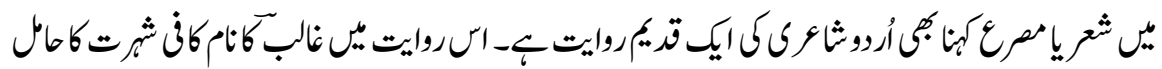

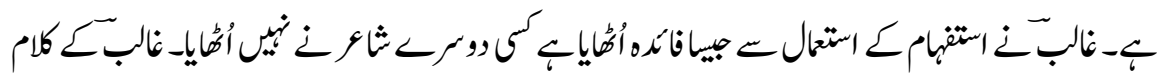

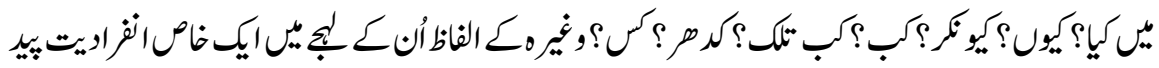
اكرتبين

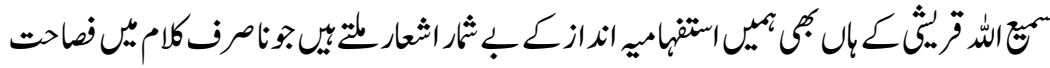

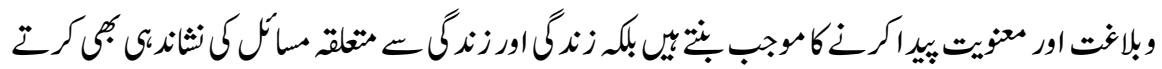




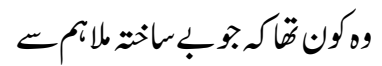

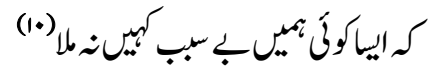

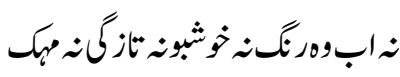

(11)

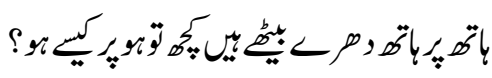

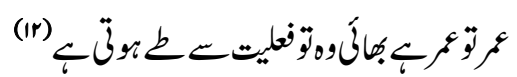

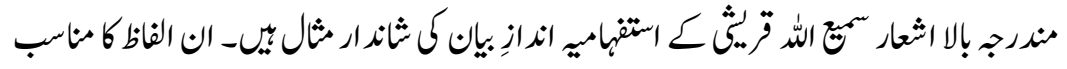

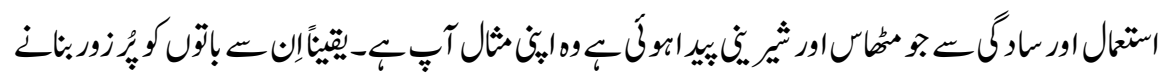

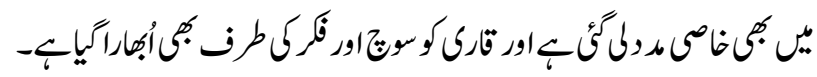

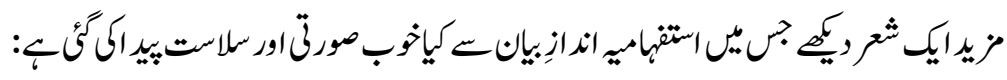

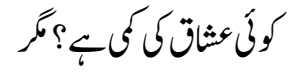

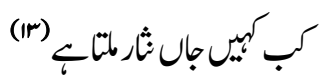

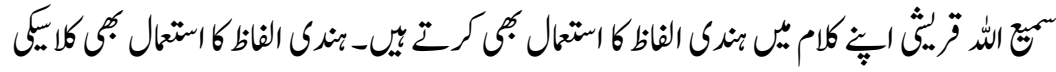

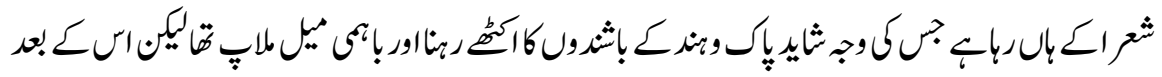

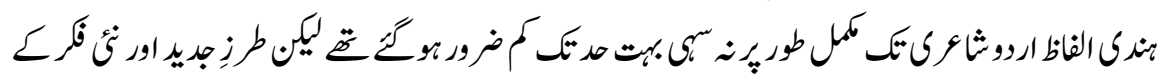

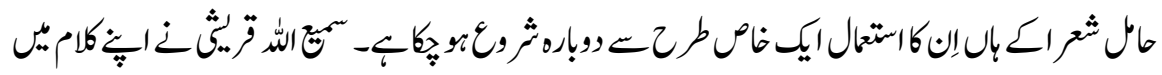

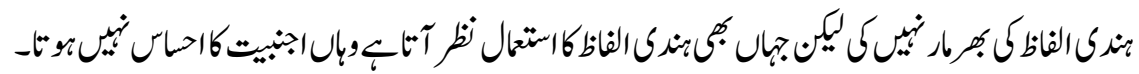

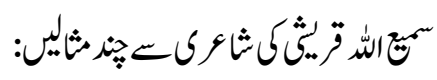

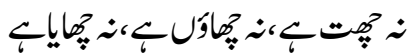

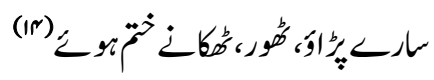

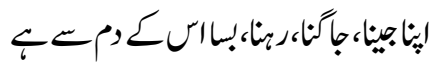

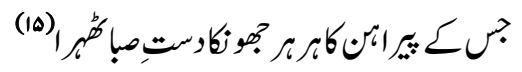


ISSN (Print): 2709-9636 | ISSN (Online): 2709-9644

Volume 2, Issue IV, (October to Decmber 2021)

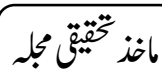

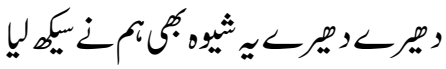

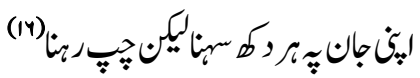

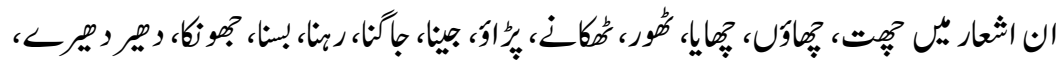

منثرى الفظأيّ-

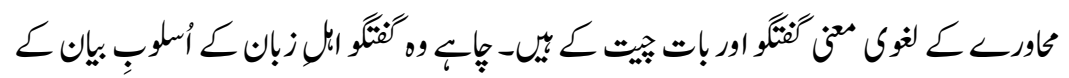

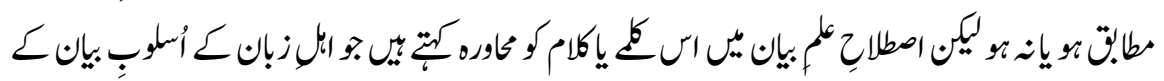

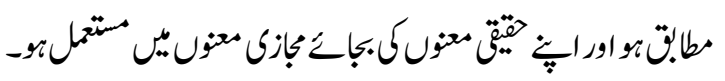

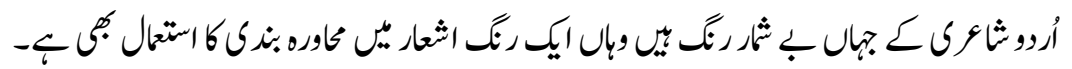

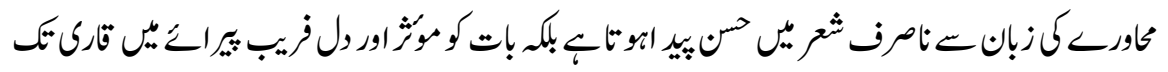

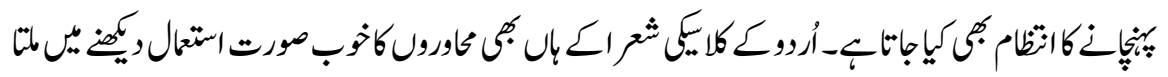

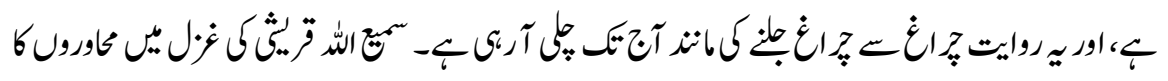

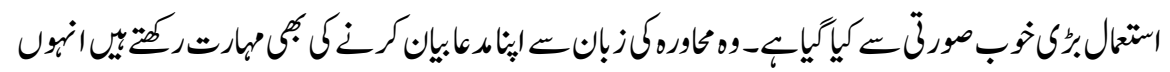

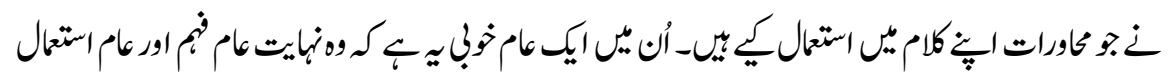

ع عاوركي:

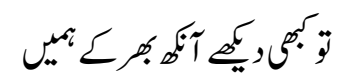

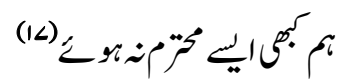

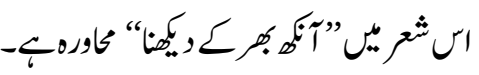

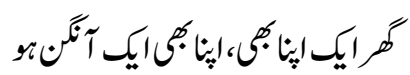

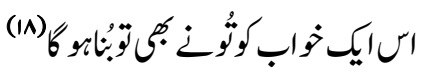

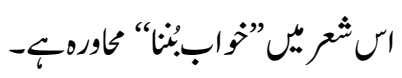

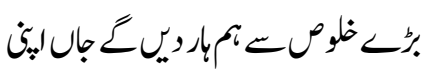

مرجول

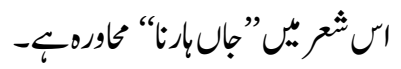

140 
ISSN (Print): 2709-9636 | ISSN (Online): 2709-9644

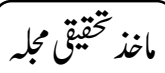

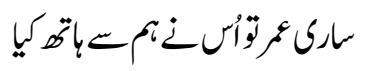

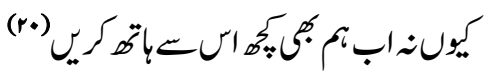

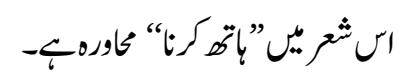

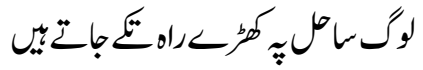

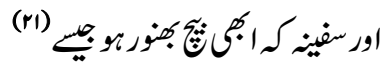

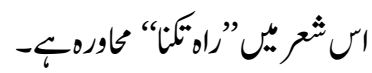

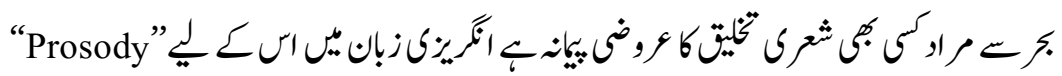

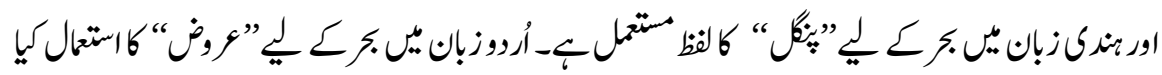

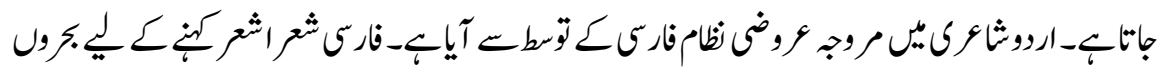

-

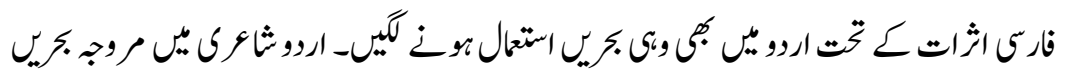

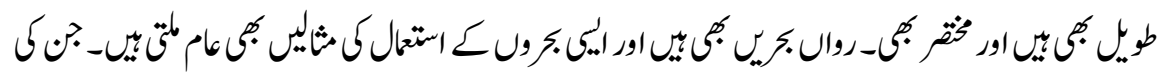

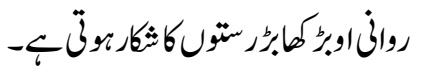

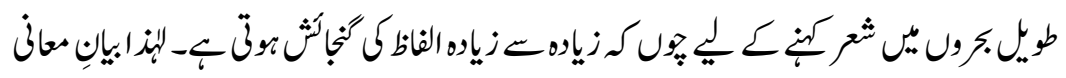

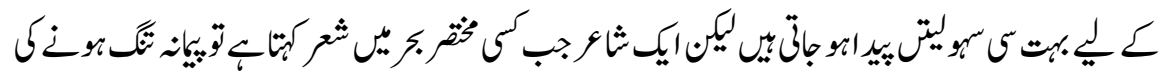

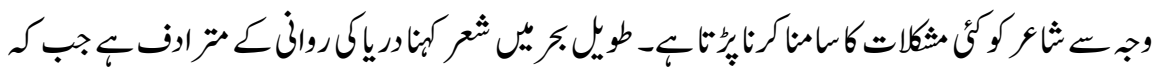

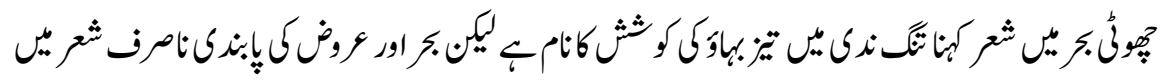

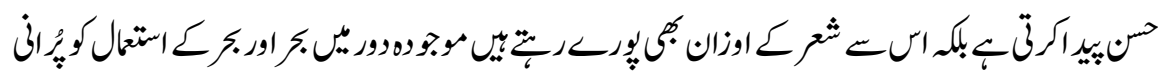

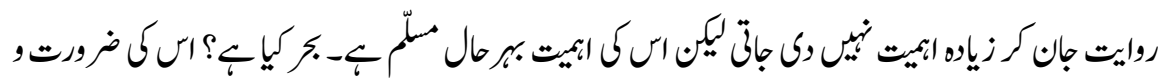

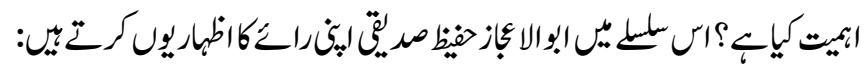

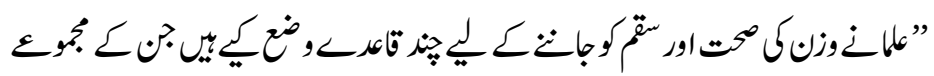

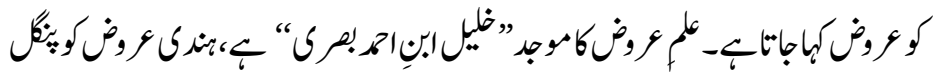

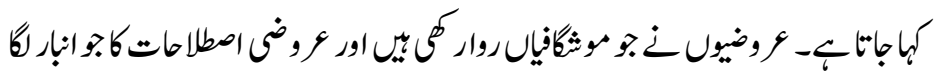

144 
ISSN (Print): 2709-9636 | ISSN (Online): 2709-9644

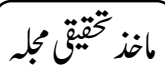

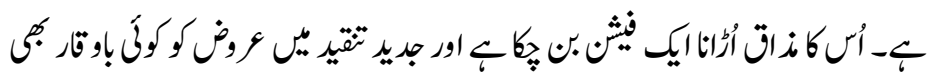

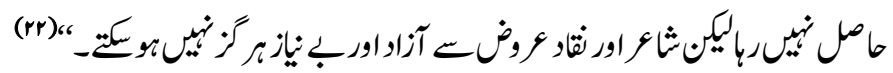

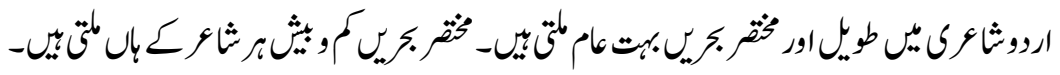

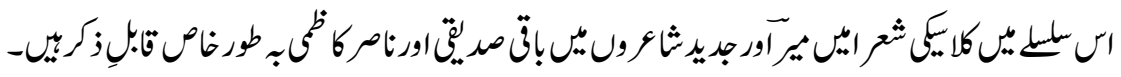

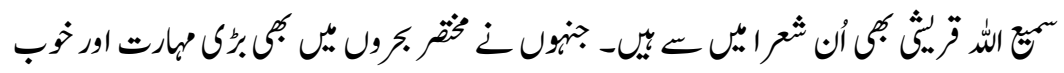

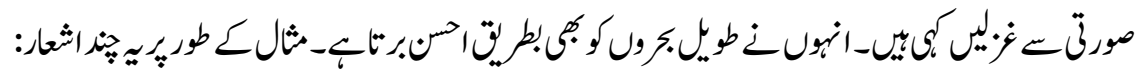

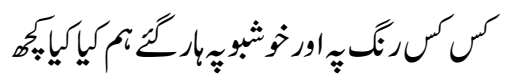

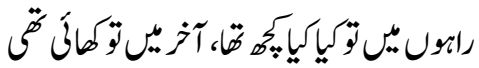

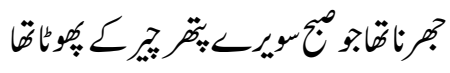

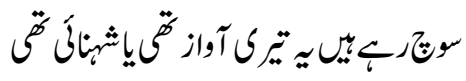

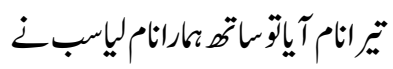

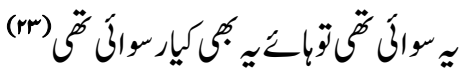

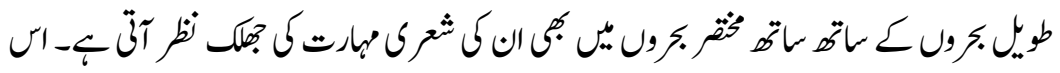

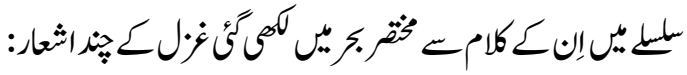

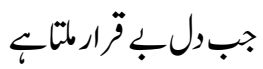

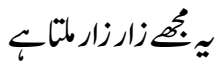

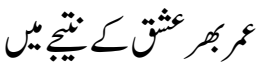

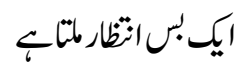

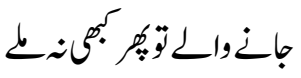

راستولكانغبارباتماك

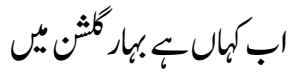

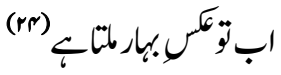

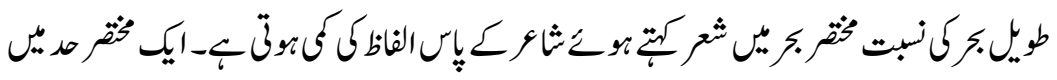

146 


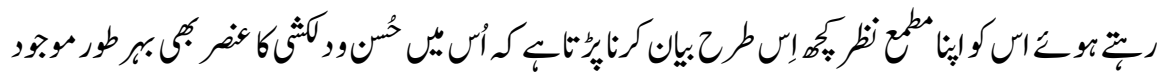

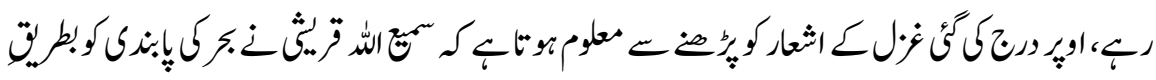

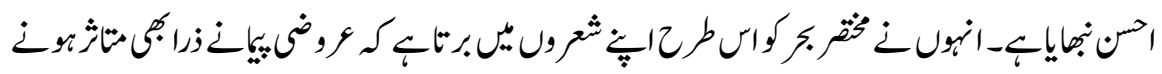

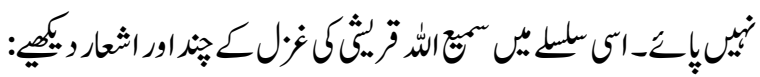

$$
\begin{aligned}
& \text { "وتقك بوابيل ليّ }
\end{aligned}
$$

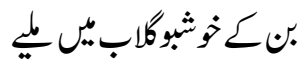

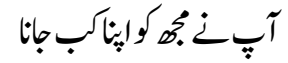

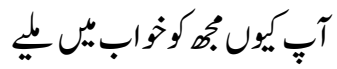

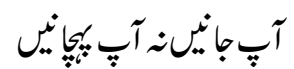

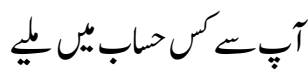

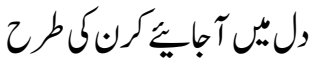

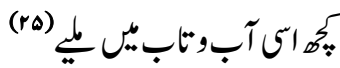

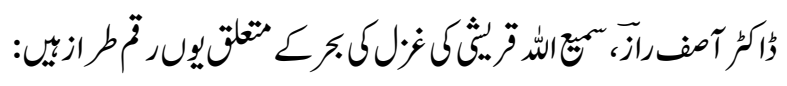

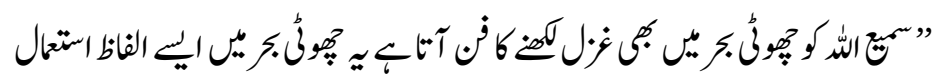

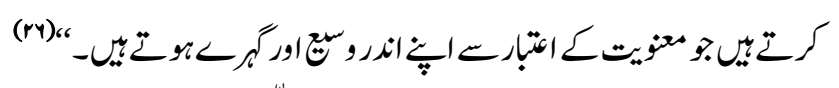

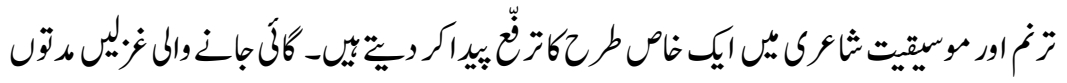

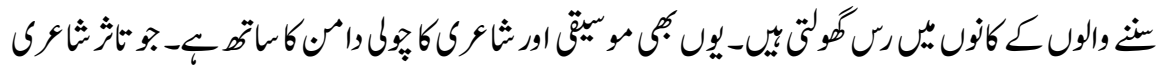

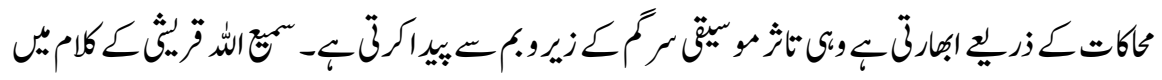

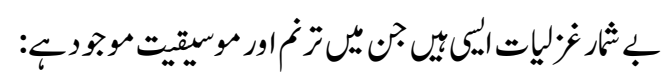

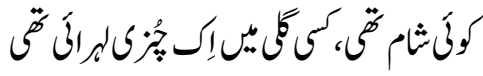

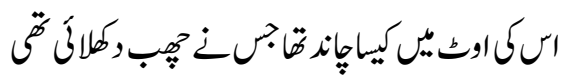

نابحن

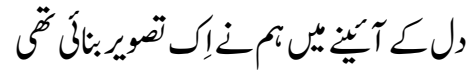




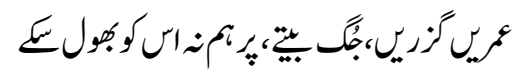

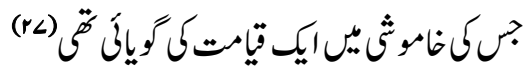

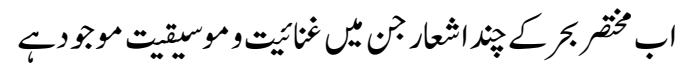

$$
\begin{aligned}
& \text { ابينيت تورهانهونى }
\end{aligned}
$$

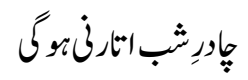

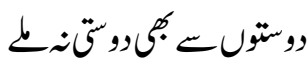

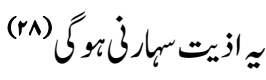

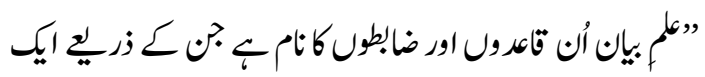

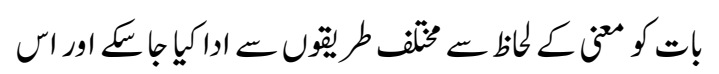

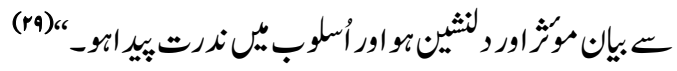

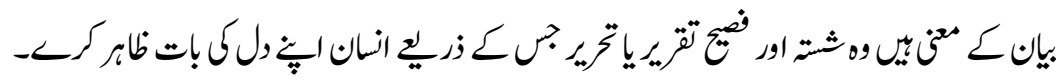

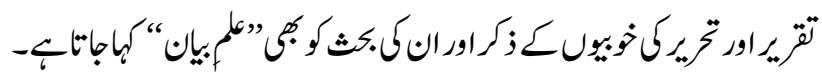

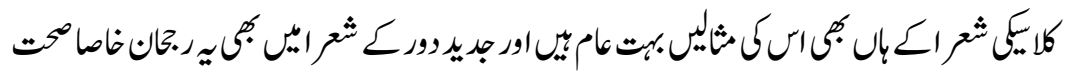

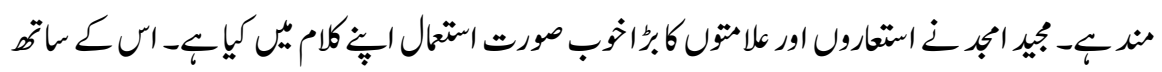

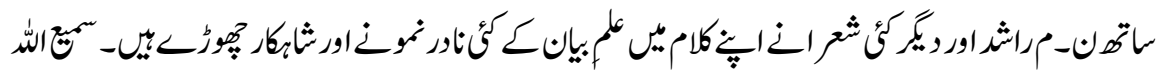

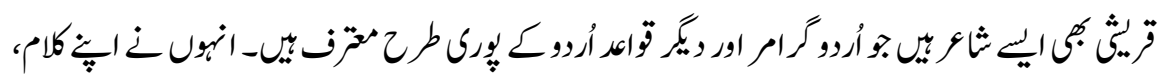

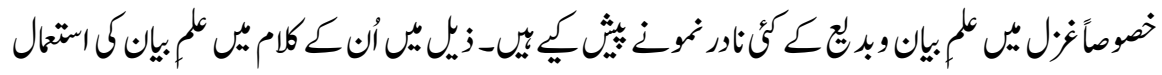

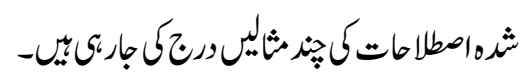

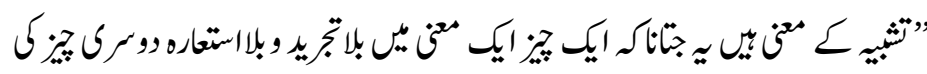

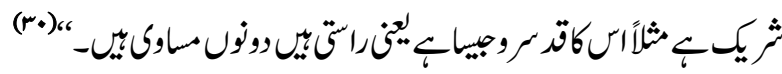

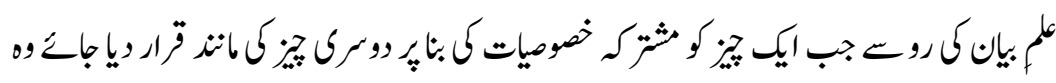

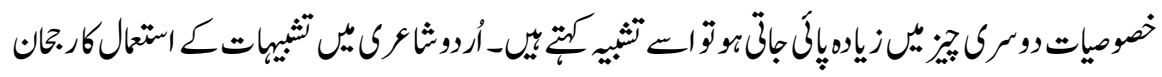

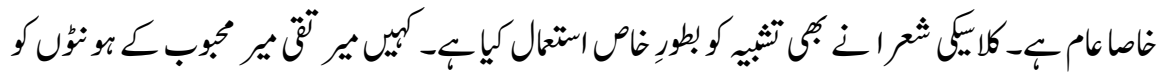




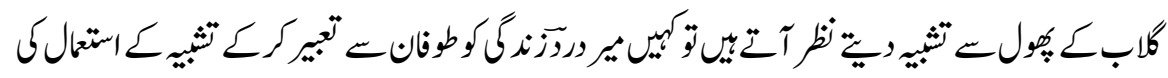

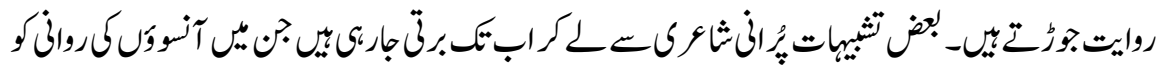

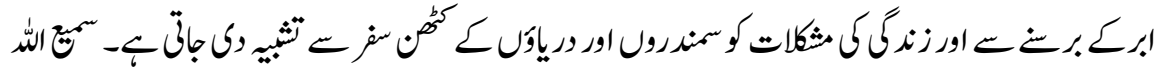

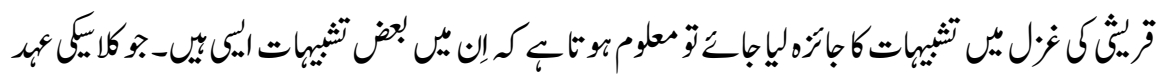

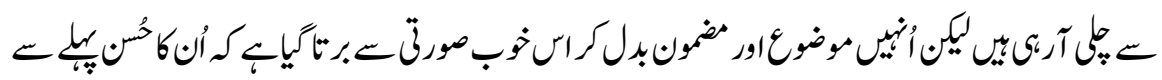

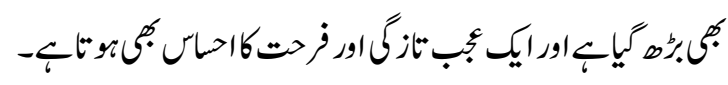

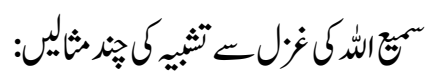

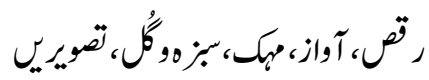

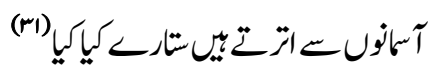

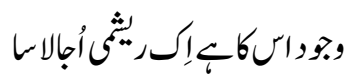
(rr)

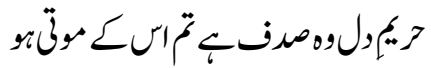
(rr)

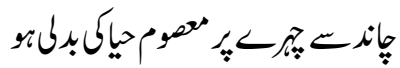

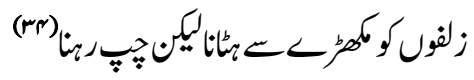

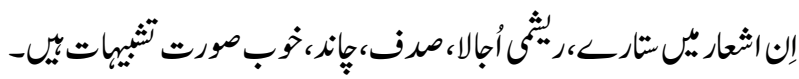

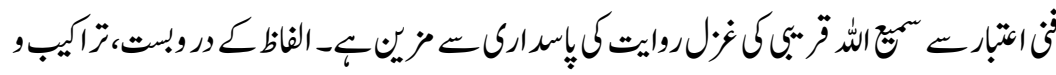

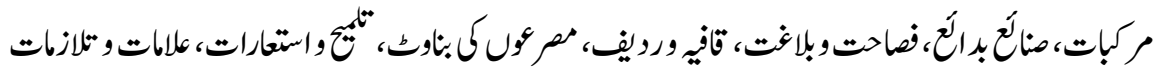

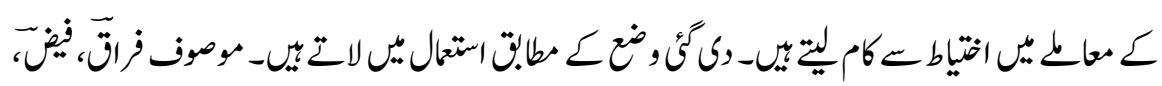

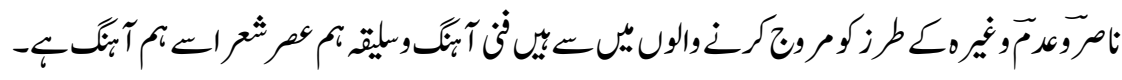




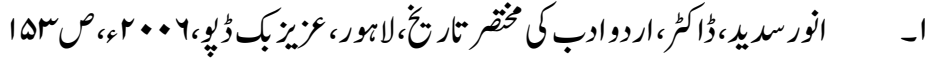

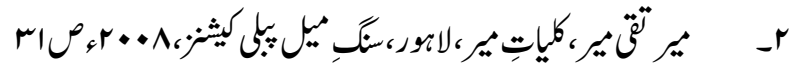

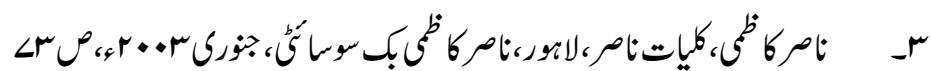

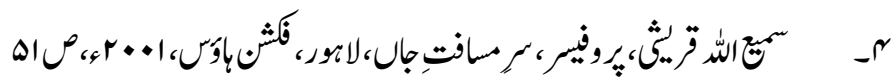

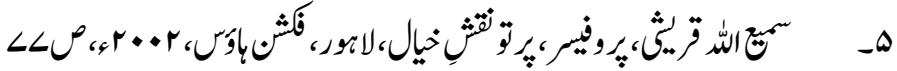

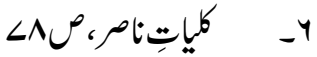

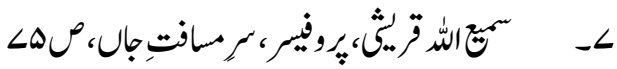

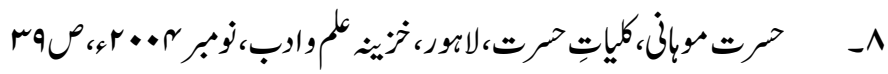

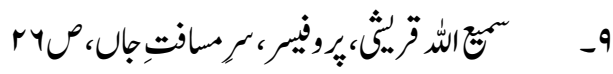

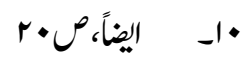

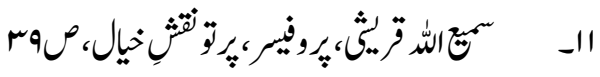

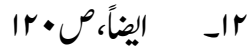

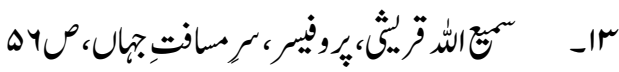

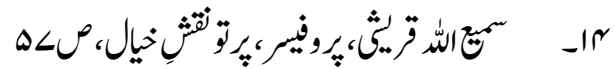

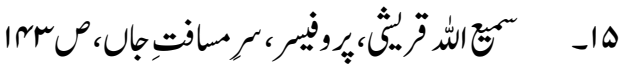

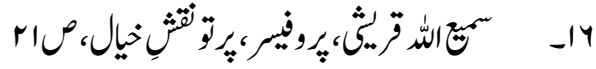

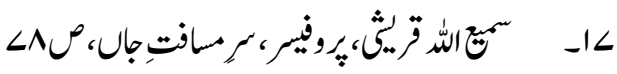

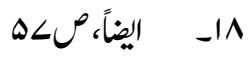

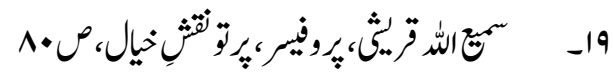$$
\text { •r }
$$

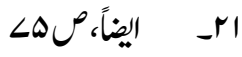

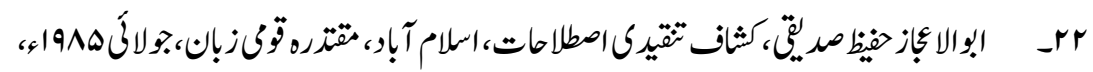




$$
\begin{aligned}
& \text { e }
\end{aligned}
$$

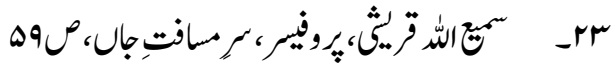

$$
\begin{aligned}
& \text { بY }
\end{aligned}
$$

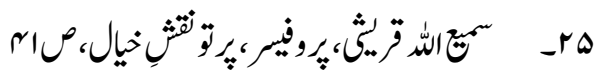

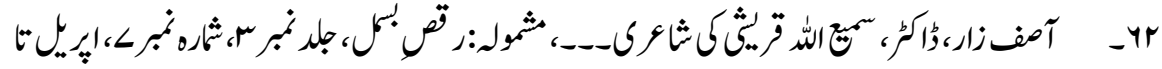

$$
\begin{aligned}
& \text { جون، }
\end{aligned}
$$

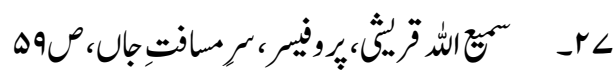

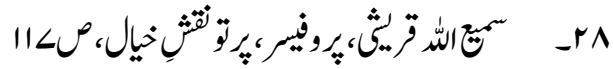

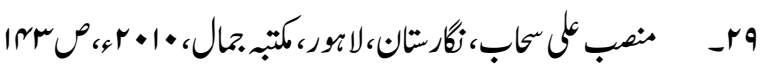

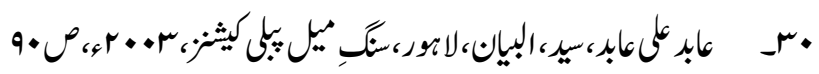

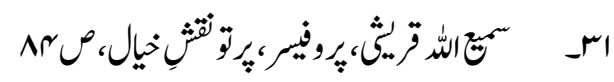

$$
\begin{aligned}
& \text { r اليضاً، صه }
\end{aligned}
$$

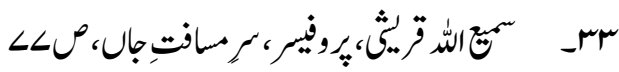

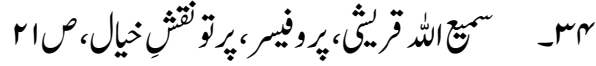

